\title{
Histórias, memórias e significados educacionais da Casa Lambert: a patrimonialização de um espaço de habitar
}

\author{
Arnaldo Pinto Junior* \\ Márcia Regina Rodrigues Ferreira**
}

\begin{abstract}
Resumo
Este artigo analisa histórias, memórias e experiências educacionais socialmente construídas na relação com o processo de patrimonialização da Casa Lambert. Considerada simbolicamente a construção mais antiga de Santa Teresa - ES, o imóvel foi tombado como patrimônio histórico e cultural em 1985. Compreendendo o patrimônio como um espaço que educa por meio do contínuo, difuso e incisivo processo de educação das sensibilidades, que envolve os sujeitos em circulação pelos diferentes cenários da cidade, a trajetória da Casa Lambert, produção material e simbólica, fornece subsídios para pensarmos a cultura como um campo de tensões, conflitos e negociações.

Palavras-chave: Patrimônio; Educação; História; Memória; Experiência.
\end{abstract}

\section{History, memories and educational meanings of the Lambert House: the patrimonialization of a residential space}

\begin{abstract}
Keywords: Patrimony; Education; History; Memory; Experience.

Uma forma completamente nova de miséria recaiu sobre os homens com esse monstruoso desenvolvimento da técnica. [...] Pois, qual o valor de todo o nosso patrimônio se a experiência não mais o vincula a nós? [...] Sim, confessemos: essa pobreza não é apenas pobreza em experiências privadas, mas em experiências da humanidade em geral Walter Benjamin (2012).
\end{abstract}

This article analyses history, memories and educational experiences socially constructed regarding the process of Lambert House's patrimonialization. Symbolically considered the oldest building in the city of Santa Teresa (Espírito Santo State), this property was declared a historical and cultural heritage in 1985. Understanding the patrimony as a space that educates continuously, diffuse and incisive process of education of the sensibilities surrounding the subject into circulation by different scenarios of the city, the path of the Lambert House, material and symbolic production, provides aids to think in culture as a field of tensions, conflicts and negotiations.

\section{Introdução}

Este artigo é resultado de um trabalho de pesquisa que abordou conhecimentos históricos e educacionais relativos à cidade de Santa Teresa, localizada na região serrana do Espírito Santo, a 78 quilômetros da capital Vitória. A proposta basilar foi, a partir do levantamento de fontes, analisar como uma casa - um espaço de habitar, que envolve as experiências dos sujeitos e expressa concomitantemente uma memória íntima e uma memória compartilhada (RICOEUR, 2007) transformou-se em patrimônio cultural da cidade e do estado. As investigações partiram de referenciais da história cultural que ampliam os olhares e as possibilidades de leitura dos espaços da urbe, constituídos por múltiplas temporalidades e constantemente reinventados por sujeitos multifacetados, dotados de racionalidade e sensibilidade.

Considerada simbolicamente a construção mais antiga de Santa Teresa, a Casa Lambert, construída entre os anos de 1875-1876 pelos irmãos trentinos Virgilio e Antônio Lambert, foi tombada em 1985 pela Secretaria de Estado da Cultura Secult e hoje funciona como um museu que procura contar a história da família Lambert e da imigração italiana no Espírito Santo.

Ao nos aproximarmos das produções do filósofo alemão Walter Benjamin, observamos os desafios que abarcam as questões patrimoniais nas complexas produções culturais do mundo contemporâneo. Tais desafios nos inspiram a buscar diálogos entre presente e passado, que considerem as experiências sensíveis dos sujeitos históricos, as descontinuidades, as rupturas e os processos de ressignificação envolvidos na patrimonialização de um espaço de habitar, transformado em símbolo de história e memória da cidade e do estado.

E compreendendo o patrimônio cultural como espaço de expressão das relações dos sujeitos históricos com a temporalidade, a cultura, a história, a memória e os processos de identificação, a Casa Lambert, no cenário sociocultural de Santa Teresa, suscita questionamentos fundamentais acerca de para

\footnotetext{
*Endereço Eletrônico: apjbrasil@hotmail.com

***Endereço Eletrônico: marciarrodrigues@live.com
} 
quem se preserva, por que se preserva e qual visão de passado é selecionada e perpetuada na transformação de um bem em patrimônio. Assim, essa reflexão é um convite para novos olhares, novas versões e novas leituras da história local que contemplem a efetiva participação dos sujeitos, seus projetos e experiências construídas coletivamente.

\section{O patrimônio cultural: problematizando práticas sociais e sensibilidades}

O patrimônio histórico e cultural, relacionado às especificidades de diferentes tempos $\mathrm{e}$ espaços, aos critérios que o selecionam e definem e às experiências plurais dos sujeitos, envolve uma interpretação da cultura como produção material e simbólica, referência de identidade, ação e memória dos diferentes grupos que formam a sociedade (FONSECA, 2009b). Nesse sentido, constitui-se como um campo investigativo fecundo para a problematização de práticas sociais que instituem visões de mundo, sociabilidades e sensibilidades.

O campo cultural é plural e constantemente reinventado. Assim, deve ser associado ao fluxo contínuo de contextos históricos específicos, localizado dentro de um equilíbrio particular de forças, em que resistências, confrontos e negociações estão sempre presentes, pois as culturas são formadas na relação com outras culturas (THOMPSON, 1998).

No tocante ao patrimônio cultural, os discursos e práticas que perpassam a ideia de um passado homogêneo e celebrativo, desconsideram esse dinamismo, movimento e complexidade que caracterizam as culturas. Permeando essas discussões, está a noção-chave no pensamento thompsoniano: experiência. Para ele,

[...] as pessoas não experimentam sua experiência apenas como ideias, no âmbito do pensamento e de seus procedimentos [...]. Elas também experimentam sua experiência como sentimento e lidam com esses sentimentos na cultura, como normas, obrigações familiares e de parentesco, e de reciprocidades, como valores ou (através de formas mais elaboradas) na arte ou nas convicções religiosas (THOMPSON, 1981, p. 189).

A perspectiva thompsoniana de cultura oferece um suporte importante para analisar as relações da sociedade com o seu patrimônio, pois se fundamenta no caráter plural da cultura e em uma acepção de sujeitos históricos inteiros, vinculados aos aspectos políticos, sociais, econômicos e culturais da realidade em que estão inseridos; indivíduos que produzem conhecimentos a partir de suas experiências, demandas e/ou efetivas condições materiais. Portanto, o referido autor fornece embasamento para a compreensão das imagens e visões de mundo presentes na Casa Lambert, espaço que representa de forma simbólica a memória e identidade italiana, capaz de despertar sentimentos de pertencimento.

Com base nessa noção de cultura, para a compreensão dos processos que elevam determinados bens à categoria de patrimônio cultural, símbolos de uma coletividade, é preciso refletir acerca da pluralidade de interesses e conflitos que perpassam as relações sociais. Os embates socioculturais estimulam "os sujeitos a acumularem experiências que são ressignificadas, promovendo ações de dominação e/ou resistência, e que levam em consideração normas, valores e sentimentos" (PINTO JR., 2010, p. 38).

Nas palavras de Thompson:

Não podemos esquecer que 'cultura' é um termo
emaranhado, que, ao reunir tantas atividades e
atributos em um só feixe, pode na verdade
confundir ou ocultar distinções que precisam ser
feitas. Será necessário desfazer o feixe e examinar
com mais cuidado os seus componentes: ritos,
modos simbólicos, os atributos culturais da
hegemonia, a transmissão do costume de geração
para geração e o desenvolvimento do costume sob
formas historicamente específicas das relações
sociais e de trabalho $(1998, p .22)$.

Mediante o exposto, a definição do patrimônio cultural depende de múltiplos fatores, entre eles, a atuação de Estado e as diretrizes dos órgãos de preservação, as escolhas dos sujeitos envolvidos, a atuação do setor privado e dos movimentos sociais e a imagem de passado que se pretende perpetuar. Por conseguinte, determinadas visões de mundo sobressaem em processos de construção simbólica que priorizam determinados bens em detrimento de outros que são legados ao esquecimento e exclusão.

A partir das ideias thompsonianas, é possível reivindicar uma aproximação entre patrimônio e experiência. Em relação aos valores, fundamentais para elucubrar questionamentos feitos ao patrimônio cultural, Thompson ressalta que são "aprendidos na experiência vivida e estão sujeitos às suas determinações" (1981, p. 194).

Conforme Thompson (1981), os valores são vividos e surgem dentro do mesmo vínculo com a vida material e as relações materiais em que surgem as nossas ideias. São as normas, regras e expectativas, entre outros, necessárias e aprendidas no ato de viver, na família, no trabalho e na 
comunidade imediata (p. 194).

As reflexões thompsonianas potencializam a análise dos processos socioculturais como espaços de constituição de sujeitos inteiros que, por meio de suas experiências, promovem rupturas e resistências capazes de ressignificar os valores e visões de mundo relacionados às tendências culturais homogeneizadoras.

\section{Usos e sentidos do espaço de habitar: percursos da Casa Lambert}

Para além de artefato construído para o abrigo humano, a casa é uma manifestação cultural que revela os modos de viver, de pensar e de agir de um grupo social, podendo adquirir vários significados a partir dos processos históricos construídos ao longo de sua trajetória e, portanto, pode ser analisada sob diversos aspectos. Nesse sentido, a Casa Lambert, permeada por valores e visões de mundo, exprime uma relação dialética entre o tempo vivido e a interpretação do passado.

A construção da Casa Lambert entre os anos de 1875-1876 insere-se no contexto do projeto modernizador de fins do século XIX e início do século XX que, entre outros aspectos, incentivou a imigração europeia para o Brasil. Nesse sentido, a arquitetura do imigrante italiano constitui parte da história de um período de intensas transformações sociais, políticas e econômicas que resultou no encaminhamento de um grande número de europeus para o Espírito Santo.
O Núcleo Timbuhy, hoje Santa Teresa, afigura-se como uma das colônias italianas fundadas nas montanhas espírito-santenses. $\mathrm{E}$ os irmãos Lambert estão entre os milhares de trentinos que deixaram o solo que os viu nascer e trouxeram para essa região seus sonhos e a esperança de melhores condições de vida. A construção do lar, do espaço de habitar, expressa seus projetos de vida, os valores culturais de sua terra natal e a necessidade de adaptação ao novo meio. Portanto, a história da imigração italiana no Espírito Santo está presente na arquitetura produzida pelos imigrantes e seus descendentes (MUNIZ, 2009).

Os imigrantes, ao construírem suas casas, além de atenderem a necessidade básica de abrigo, infundiram nelas valores afetivos, conhecimentos, expectativas e visões de mundo (FILIPPON, 2007). Por conseguinte, a moradia revela as relações dos indivíduos com o espaço vivido, sendo possível analisá-la para além de artefato construído para abrigo, como um objeto que pode adquirir vários significados, e que tem a sua própria linguagem e representação (FILIPPON, 2007, p. 9).

A Casa dos irmãos Lambert (Figura 1) foi construída utilizando a técnica de pau a pique, também conhecida como taipa de mão ou estuque, tanto interna quanto externamente. Apresenta dois pavimentos de planta retangular e armação de taipa com varas colocadas no sentido diagonal. É considerada por Muniz (1998) como referência de construção reforçada e também de manutenção de tradições culturais do Trentino.

Figura 1- Fotografia da Casa Lambert no início do século XX

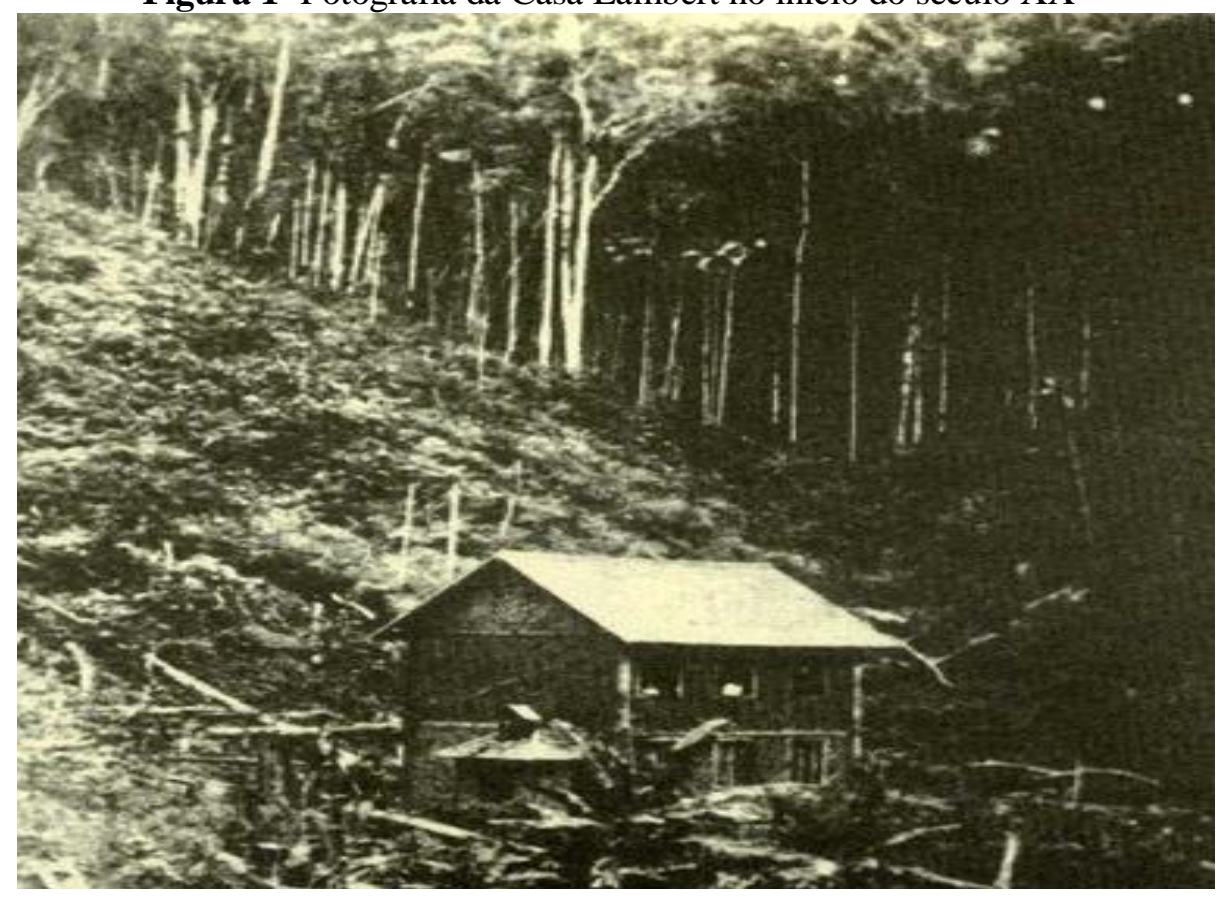

Fonte: Grosselli (2008). Autor desconhecido. 
A técnica de pau a pique predominou na arquitetura rural do imigrante italiano e foi conhecida logo após sua chegada, pois era utilizada nos barracões que os abrigavam (MUNIZ, 1998). Entretanto, os italianos a aperfeiçoaram, desenvolvendo inovações que garantiram a construção de moradias mais resistentes. Assim, a técnica usada na região "recebeu um gradeado feito com ripas estruturadas na diagonal [...], o que proporcionava mais estabilidade às paredes de pouca espessura, tanto internas quanto externas" (MUNIZ, 1998, p. 257).

A madeira de lei, extraída da floresta virgem que cobria as suas novas terras, foi o principal material utilizado pelos colonos na construção das casas. Com ela eram feitas as estruturas, esquadrias, pisos, coberturas, forros, balaústres, escadas e ornamentação (MUNIZ, 1998; POSENATO, 1998).

Por meio dos escritos de Muniz (1998), é possível conhecer mudanças ocorridas na Casa Lambert ao longo do tempo.

[...] o volume que constituía uma pequena cozinha, como no Trentino, já não existe; e a escada para o sótão também já se perdeu. A base de pedra, a estrutura em madeira e as paredes de pau-a-pique reforçadas por ripas na diagonal permaneceram aparentes, como sempre foram (MUNIZ, 1998, p. 265).

Tombado como patrimônio histórico e cultural do Espírito Santo em 1985, o imóvel manteve seu uso original como moradia até 2007, quando foi comprada dos herdeiros para ser transformada em um espaço cultural.

A expressão tombamento é originária do direito português na qual o verbo tombar significava inventariar ou inscrever nos arquivos do reino, que ficavam guardados na Torre do Tombo. Instrumento de preservação por excelência da política patrimonial implementada no Brasil na década de 1930, muitas vezes confundido com a preservação, o tombamento significava inscrever em um dos quatro livros do Tombo: Livro de Belas-Artes, Livro Histórico, Livro Arqueológico e Etnográfico, e Livro Paisagístico (OLIVEIRA, 2008).

E se as décadas de 1970 e 1980 marcaram o surgimento de novas concepções de patrimônio e preservação, essas ideias não chegaram a alterar substancialmente as práticas de preservação. Mesmo o artigo 216 da Constituição Federal de 1988 indicando explicitamente a busca de "outras formas de preservação e acautelamento", a prática do Instituto do Patrimônio Histórico e Artístico Nacional - Iphan continuou concentrada nos tombamentos (FONSECA, 2009a).
Fonseca (2009a) ressalta que [...] o instituto do tombamento - dispositivo por meio do qual, no decreto-lei $\mathrm{n}^{\mathrm{o}} 25$ de 30.11 .37 , se efetiva a proteção de bens culturais pelo Estado no Brasil - incide sobre o sistema de valores dos bens por ele atingidos e sobre o estatuto da propriedade desses bens de forma peculiar, específica (p. 38).

Ainda segundo Fonseca (2009a), na concepção atual, "além de instrumento jurídico com implicações econômicas e sociais, o tombamento tem sido considerado e utilizado, tanto por agentes oficiais quanto por grupos sociais, como o rito, por excelência, de consagração do valor cultural de um bem" (p. 180).

No que se refere à Casa Lambert, é importante analisar o tombamento a partir de suas "implicações na vida social, ou seja: o uso que dela fazem os agentes oficiais; o modo como dela se apropriam os que a solicitam; as reações daqueles que são afetados por sua aplicação ou pelo não atendimento desse tipo de solicitação" (FONSECA, 2009a, p. 181).

As primeiras movimentações em defesa do tombamento de bens pertencentes à família Lambert ocorreram a partir da primeira metade da década de 1980, fundamentadas em valores de ordem histórica e cultural e enfatizando o caráter de referência desses bens para o processo de imigração italiana no Espírito Santo.

A importância do imóvel foi destacada também por ter abrigado os Lambert, imigrantes que deram grandes contribuições à região e ao estado, cujos descendentes continuavam morando na casa e zelando pela sua preservação. O tombamento era considerado como uma relevante iniciativa no sentido de destacar Santa Teresa como um dos municípios de imigração italiana, com grande influência de sua cultura (CONSELHO ESTADUAL DE CULTURA, Processo de Tombamento 09/80, p. 10-11).

Assim, o processo de tombamento sustentava-se na ideia da casa "enquanto testemunho de um determinado espaço/tempo vivido por determinados atores" (FONSECA, 2009a, p. 42). Todavia, é importante considerar que a constituição do patrimônio é uma prática essencialmente seletiva, restrita a especialistas, que atuam em nome do interesse público, e acabam privilegiando uma concepção tradicional da história, que numa dimensão instrumental não abarca a complexidade, as tensões e os conflitos dos diferentes contextos em que estão inseridos os bens patrimoniais.

O parecer favorável ao tombamento da Casa dos Lambert, da Capela de Nossa Senhora da Conceição, três crucifixos e uma imagem de Nossa Senhora da Conceição, todos de propriedade da 
família Lambert, referente ao processo $\mathrm{n}^{\circ}$ 09/80 do $\mathrm{CEC}$, foi apresentado e aprovado na $551^{\mathrm{a}}$ reunião plenária do referido Conselho, no dia 5 de junho de 1984. Na sequência, a Resolução $n^{\circ}$ 07/85 do CEC, de 12 de dezembro de 1985, tendo em vista o que consta no processo $\mathrm{n}^{\circ}$ 09/80-CEC, aprova em caráter definitivo o tombamento:

a) da residência da família Lambert com suas paredes e revestimentos internos situada na sede do município de Santa Teresa, inscrita no Livro de Tombo Histórico sob o número 83, f. 9v. e 10 e no Livro de Tombo das Belas Artes sob o $n^{\circ} 57$, f. $14 \mathrm{v}$ e 15 ;

b) da capela de Nossa Senhora da Conceição, situada na sede do Município de Santa Teresa inscrita no Livro de Tombo Histórico sob o número 86 às f. 9v e 10 e no Livro de Tombo das Belas Artes sob o Número 60 às f. 14v e 15;

c) da imagem de Nossa Senhora da Conceição em madeira, existente na capela homônima, situada na sede do Município de Santa Teresa, estando a referida imagem inscrita no Livro de Tombo das Belas Artes sob o número 58 às f.14v e 15;

d) de três crucifixos em madeira existentes na residência da Família Lambert, situada na sede do município de Santa Teresa, estando os referidos crucifixos inscritos no Livro de Tombo das Belas Artes sob o número 59 às f. $14 \mathrm{v}$ e 15. (CONSELHO ESTADUAL DE CULTURA, Resolução n ${ }^{\circ}$ 07/85).

As medidas de preservação do espaço da Casa Lambert ligadas ao interesse público e aos valores culturais reiteradamente apresentados em pareceres e dossiês que tramitaram durante o processo de tombamento, não se efetivaram. Em 1986, um ofício enviado pelo Secretário do CEC, Fernando Achiamè, ao então prefeito de Santa Teresa, Ethevaldo Damazio, destaca ameaças de descaracterização da casa devido à construção em seu entorno (CONSELHO ESTADUAL DE CULTURA, Processo de Tombamento $n^{\circ}$ 09/80), o que evidencia que os processos de tombamento afetam a organização dos diferentes espaços da cidade e os seus usos sociais e que uma política de preservação do patrimônio é bem mais ampla que a proteção representada pelo tombamento.

Outro aspecto amplamente discutido desde o tombamento da Casa Lambert é a proximidade com a estrada São Lourenço e o intenso tráfego de caminhões que produzem trepidações que afetam a estabilidade do imóvel. O Projeto de Restauração da Casa Lambert produzido em 2008 pela Secult destaca a situação supracitada como um dos fatores que contribuiu para os problemas estruturais que o imóvel apresentava naquela ocasião.

Por volta do ano 2000, ganham destaque os problemas apresentados pelo imóvel e a necessidade de restauração, o que revela que nos quinze anos posteriores ao tombamento não foram efetivadas medidas que garantissem a preservação do imóvel, ficando sua conservação exclusivamente sob a responsabilidade da família. A situação de deterioração da Casa nos anos 2000 abre brechas a indagações sobre o reconhecimento e valoração do imóvel por parte do poder público e da sociedade, após o tombamento.

Os aspectos explicitados acima evidenciam que as políticas de preservação do patrimônio cultural transcendem o conjunto de atividades visando a proteção física do bem e os recursos viabilizados pelas leis, decretos ou portarias dos órgãos estatais de patrimônio (FONSECA, 2009a).

$\mathrm{E}$ diante das diversas problemáticas que envolvem a questão patrimonial no mundo contemporâneo, é importante assinalar a convivência de situações díspares: se por um lado os bens patrimoniais têm sido exaltados como forma de preservar a história e memória coletiva, por outro, a ideia de preservação, em meio a valores instaurados pela modernidade capitalista, tem resultado em experiências e memórias fragilizadas. Os atos de conhecer, guardar, colecionar e lembrar antigos costumes e tradições cada vez mais crescentes, geralmente vem acompanhados da ideia de bens intocáveis, uma visão nostálgica de lugares pitorescos a serem visitados. Conforme Meneghello, "cada vez mais conhecido o passado parece ser cada vez menos compartilhado" (2000, p. 396).

Retomando a trajetória histórica da Casa Lambert, o Projeto de Restauração da Casa Lambert, elaborado em 2008, foi uma parceria entre a Secult e a Prefeitura Municipal de Santa Teresa. Nos argumentos que fundamentaram a necessidade da restauração e consequente preservação, o imóvel tombado é apresentado como um bem patrimonial de elevado valor para a história do Espírito Santo por diversos aspectos, entre eles: o fato de ser remanescente do processo de imigração italiana na região, a peculiar característica construtiva original de dois pavimentos integralmente em estuque e a figura de seus proprietários, os irmãos Lambert, com sua produção artística (CONSELHO ESTADUAL DE CULTURA, Processo de Restauração $n^{\circ}$ 43150837/08).

Em relação à situação do imóvel, o Projeto destaca que estava desocupado e em processo de desapropriação pela prefeitura. Dessa forma, o estado de degradação do imóvel suscitou a desocupação, pois vinha "oferecendo riscos à segurança de seus usuários e, consequentemente à própria permanência 
do bem no cenário da cidade, como testemunho vivo de sua história" (CONSELHO ESTADUAL DE CULTURA, Processo de Restauração $n^{\circ}$ 43150837/08, p. 6).

Para a criação desse espaço de memória dos irmãos Lambert e da imigração italiana, o documento reforça a necessidade de realizar cadastramento que reúna dados relativos à história da casa e de seus proprietários, registros gráficos e iconográficos da arquitetura, além de estudos e análises que enriqueçam o conhecimento já sistematizado. No Projeto, a criação do centro de memória é assim justificado:

Esse registro e a sua divulgação através de e no próprio bem objeto de intervenção tem sido premissa básica no trabalho de preservação do patrimônio histórico e cultural brasileiro. Com isso, ele (o bem) participa ativamente do processo de resgate e preservação da memória histórica e cultural do Estado do Espírito Santo, na forma de contrapartida social, contribuindo com a Educação Patrimonial e potencializando as atividades turísticas na região (CONSELHO ESTADUAL DE CULTURA, Processo de Restauração n ${ }^{\circ} 43150837 / 08$, p. 11).

Ao dialogarmos com as visões benjaminianas, questionamos a ideia de resgate apresentada no documento, relacionada às concepções tradicionais e dominantes de patrimônio que apresentam o passado e a história como locais pitorescos a serem visitados.

$\mathrm{O}$ resgate do passado de forma pura e intocável é contrário à ideia da ressignificação, que considera os sujeitos do presente como forças ativas que têm papel fundamental na atribuição de significados ao bem cultural. A preservação, enquanto resgate de um legado, não permite uma relação dialética entre as dimensões do presente e passado. Para Benjamin "é uma imagem irrecuperável do passado que ameaça desaparecer com cada presente que não se sinta visado por ela" (2014, p. 243).

O Projeto de Restauração da Casa dos Lambert estava fundamentado na preservação da memória dos irmãos Lambert e da imigração italiana na região de Santa Teresa por meio da restauração e consolidação dos suportes físicos, ou seja, a casa de pau a pique, a oficina e a capela (CONSELHO ESTADUAL DE CULTURA, Processo de Restauração no 43150837/08, p. 66). Cabe ressaltar, todavia, com base na noção thompsoniana de experiência, que é necessário focalizar os sujeitos nos processos históricos, os quais, por meio de suas ações, (re) inventam e (re) significam os bens patrimoniais, que devem produzir sentidos culturais à temporalidade contemporânea.

De acordo com a perspectiva que sustenta o projeto de Restauração "a história é contínua, e como tal, seus testemunhos de valor devem ser preservados" (CONSELHO ESTADUAL DE CULTURA, Processo de Restauração $\mathrm{n}^{\circ}$ 43150837/08, p. 66).

Mais uma vez nos aproximamos de Benjamin (2012), que em seus escritos tece críticas às noções de continuidade, causalidade e progresso presentes na razão histórica moderna. Para esse autor, "a ideia de um progresso da humanidade na história é inseparável da ideia de seu andamento no interior de um tempo vazio e homogêneo. A crítica da ideia desse andamento deve estar na base da crítica da ideia do progresso em geral"' (2012, p. 249).

O Projeto de Restauração da Casa Lambert foi apresentado e aprovado pela Câmara de Patrimônio Arquitetônico, Bens Móveis e Acervos do CEC, em 21 de novembro de 2008. Aberta à visitação em 2011, a Casa (figura 2) afigura-se como um dos cartões-postais da cidade, atraindo crianças e jovens de escolas do próprio município e de outras cidades do estado, além de turistas que buscam o clima de montanha, as belas paisagens e elementos da cultura italiana presentes em Santa Teresa. 
Figura 2- Fotografia da Casa Lambert nos dias atuais

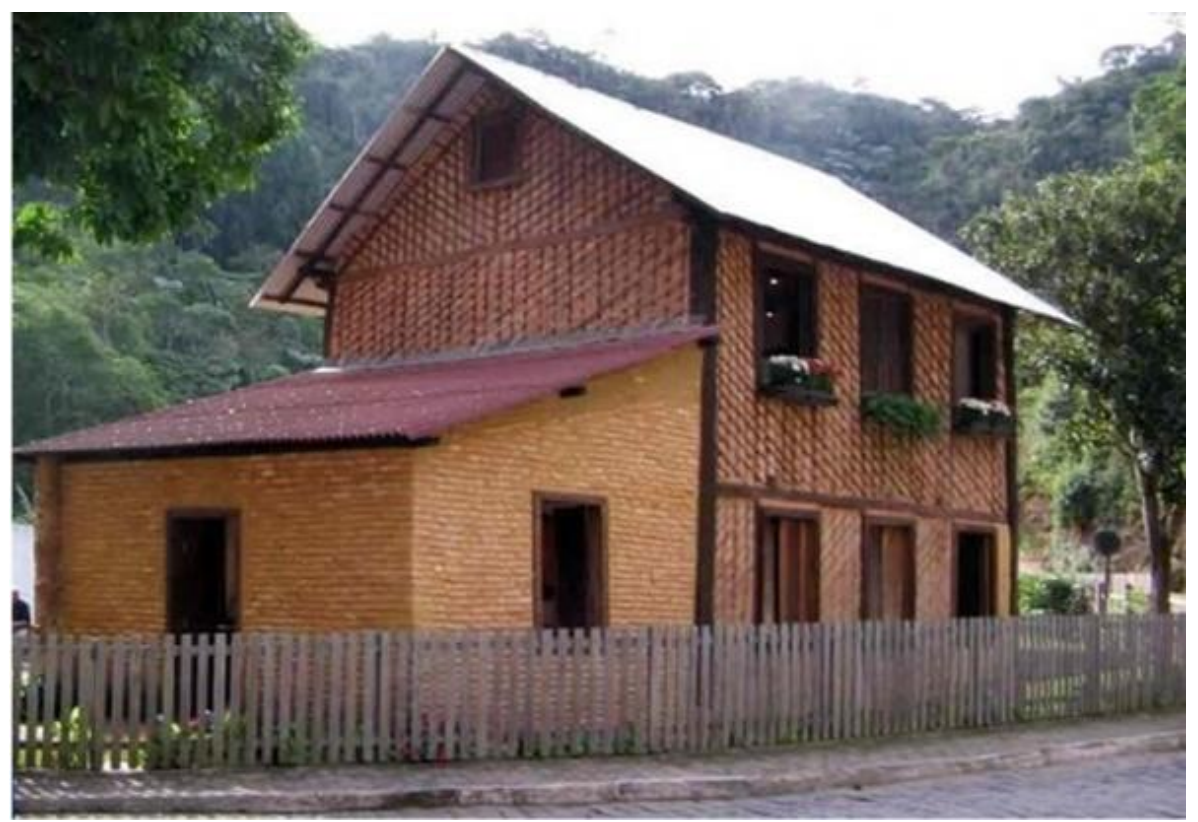

Fonte: Lordello (2013).

\section{O patrimônio na perspectiva da educação das sensibilidades}

As discussões sobre o processo de patrimonialização da Casa Lambert encontram no historiador Peter Gay (1988) referências fundamentais para analisar os processos de constituição dos sujeitos na modernidade.

Para Gay (1988), o sujeito histórico, dotado simultaneamente de racionalidade e sensibilidade, define suas formas de agir e pensar o mundo em práticas culturais plurais, entre as quais destacamos a constituição dos patrimônios. Amalgamando temporalidades múltiplas, a Casa Lambert, outrora um lar e hoje patrimônio da cidade, está historicamente integrada às transformações oriundas dos ideais difundidos pela modernidade, que educa para fins específicos, entre eles, o acelerado processo de urbanização das últimas décadas.

$\mathrm{Na}$ perspectiva analítica proposta por Gay (1988), a cultura está relacionada a toda realização humana que contribui para a experiência, um processo complexo de relações sociais em movimento.

Hadler (2007, p. 21) ressalta que para o autor supracitado,

[...] o processo de formação de uma visão de mundo é constante, sempre inacabado, sempre em constituição; é um processo, de fato, de formação, de educação, uma educação que não se circunscreve apenas aos domínios da racionalidade intelectual técnica, da consciência objetiva, mas que atinge e perpassa os campos mal definidos da sensibilidade, tanto no que ela tem de mais visível quanto de mais escondido e secreto.

Por conseguinte, a vida em sociedade e todas as realizações humanas contribuem para a experiência que constitui "o encontro da mente com o mundo" e também "do passado com o presente" e, dessa forma, as "experiências comprovam a existência de um tráfego ininterrupto entre o que o mundo impõe e o que a mente exige, recebe e reformula" (GAY, 1988, p. 19). Trata-se de uma educação vivenciada cotidianamente por meio de estímulos de natureza diversa, provenientes da circulação por diferentes espaços, um processo contínuo de ouvir e observar que produz significados e modela de forma sutil e silenciosa as sensibilidades e visões de mundo dos sujeitos.

De acordo com Pinto Jr. (2010), a perspectiva de educação dos sentidos desenvolvida por Gay apresenta uma concepção ampliada de ser sujeito e de cultura, abrangendo uma dimensão consciente e também inconsciente. Assim, "a cultura é vista em sua obra como um processo contínuo, difuso e contraditório, de produção de visões de mundo e formas de sensibilidade e sociabilidade" ( $p$. $34)$.

Entre as questões que envolvem o patrimônio cultural diante das sensibilidades e sociabilidades engendradas pela modernidade está o turismo cultural e uma ideia de patrimônio como espaço ritualizado e estetizado. $\mathrm{O}$ visitante dá preferência ao 
estético em detrimento das mensagens históricas e, assim, o patrimônio torna-se uma mercadoria passível de ser consumida (OLIVEIRA, 2005).

Conforme Gonçalves (2009b), nas elaborações benjaminianas sobre o declínio da experiência na modernidade, aparecem dois personagens típicos desse contexto: o flâneur e o homem-da-multidão, representando formas específicas de reagir ao célere ritmo das grandes cidades e sua impessoalidade. O flâneur e o homemda-multidão podem ser identificados na relação dos sujeitos com o seu patrimônio cultural.

Benjamin (1985, p. 39), ao analisar as transformações ocorridas em Paris no século XIX, assim define o olhar do flâneur:

[...] o olhar alegórico a perpassar a cidade é o olhar do estranhamento. [...] É o olhar do flâneur, cuja forma de vida envolve com halo reconciliador a desconsolada forma de vida vindoura do homem da cidade grande. O flâneur ainda está no limiar tanto da cidade grande quanto da classe burguesa. Nenhuma delas ainda o subjugou. Em nenhuma delas ele se sente em casa. Ele busca o seu asilo na multidão. [...] A multidão é o véu através do qual a cidade costumeira acena ao flâneur enquanto fantasmagoria.

Se o flâneur recusa-se a ser absorvido pelo ritmo vertiginoso das grandes cidades e a perder sua subjetividade, o homem-da-multidão se deixa levar pelo movimento, sem interesse ou curiosidade pelo que ocorre a sua volta. Desse modo, o homem da multidão pode ser descrito como

[...] aquilo que aconteceria ao flâneur se lhe fosse retirado seu ambiente. A intensificação dos processos característicos da grande cidade, a vasta heterogeneidade de códigos socioculturais, a intensificação da atitude psicológica de reserva do habitante da grande cidade, o aumento do tráfego e do ritmo de deslocamento da população inviabilizam a experiência do flâneur [...]. O 'homem-da-multidão', em contraste com o flâneur, identifica-se com a multidão e seu ritmo vertiginoso (GONÇALVES, 2009b, p. 175).

Para Oliveira (2005), o patrimônio estimula e excita os sentidos dos diferentes indivíduos, possuindo uma importante função agregadora e, nesse sentido, possibilita aproximações com as figuras do homem-da-multidão e do flâneur. Permeando essa assertiva está o processo de educação das sensibilidades e a compreensão de que o patrimônio permite a análise histórica de múltiplas épocas, memórias diversas e experiências individuais ou coletivas.

Entre os rastros e possibilidades de construção de saberes na relação da cidade com suas memórias e patrimônios, analisar o processo de patrimonialização da Casa Lambert na perspectiva da educação das sensibilidades é pensá-la no diálogo com as experiências de sujeitos inteiros, construídas em relações sociais plurais.

Segundo o antropólogo José Reginaldo Santos Gonçalves (2009a), o patrimônio, como uma categoria de pensamento, "não existe apenas para representar ideias e valores abstratos e ser contemplado". Para ele, "o patrimônio, de certo modo, constrói, forma as pessoas" (p. 31).

Nesse sentido, a partir das contribuições teóricas da educação das sensibilidades, é possível pensar, a contrapelo de tendências homogeneizadoras e dominantes, em imagens dialéticas e plurais de conhecimentos históricos produzidos por meio do patrimônio, reverberando em experiências que produzam momentos criativos e significativos que rompam com as vivências automatizadas inauguradas pela modernidade capitalista. Os patrimônios culturais podem "inspirar a produção de experiências [...] comprometidas com o absoluto dos seres humanos" (GALZERANI, 2013, p. 105).

\section{Considerações Finais}

$\mathrm{Na}$ tessitura deste artigo apresentamos reflexões acerca da transformação da Casa Lambert em patrimônio cultural de Santa Teresa e do Espírito Santo. Com base no conceito de educação das sensibilidades, a patrimonialização dessa residência foi compreendida como um processo historicamente construído que envolveu práticas racionais $\mathrm{e}$ sensíveis (GAY, 1988).

Constituída por temporalidades múltiplas, a Casa Lambert, no contexto sociocultural de Santa Teresa, foi sobremaneira estimulante para a realização de um diálogo entre presente e passado que considerasse os diferentes espaços que atuam na nossa educação, isto é, na formação de pessoas inteiras.

No ano de 1985, a Casa Lambert foi tombada como patrimônio histórico e cultural pela Secult. O tombamento, cujos efeitos são materiais e simbólicos, revela tensões e conflitos, sejam eles explícitos ou não, que podem ser identificados no surgimento de novas sensibilidades e sociabilidades. Em 2007, devido ao estado de degradação em que se encontrava, o imóvel foi desocupado, rompendo com o uso residencial historicamente consolidado. Restaurado em 2010, foi transformado num museu.

Definido como símbolo da história e 
memória da imigração italiana em Santa Teresa e no Espírito Santo, esse espaço está relacionado à conformação de uma determinada versão da história da cidade. E no diálogo com os pressupostos teóricos da educação das sensibilidades, esse processo reverbera uma determinada percepção do que deve ser considerado patrimônio da cidade, em detrimento de outros bens que não são dotados da carga simbólica da referida casa, identificada como a mais antiga da cidade e, nesse sentido, enraizada em um tempo histórico específico.

Assim, considerando que vivenciamos um processo ininterrupto de educação das sensibilidades que na maioria das vezes nos estimula a esquecer, apagar, excluir e silenciar as memórias e histórias plurais (GAY, 1988; HADLER, 2007; PINTO JR., 2010; THOMPSON, 1981), o patrimônio, como espaço multifacetado e atravessado por múltiplos significados e diferentes temporalidades, possibilita a problematização das visões de mundo construídas ao longo da trajetória histórica da cidade.

Com base nas formulações teóricas de Benjamin, é fundamental salientar que na modernidade estamos enredados numa realidade social caracterizada pelo esfacelamento das relações sociais, pela dilapidação da memória e pelo esvaziamento de experiências coletivas que permeiam a apreensão da cidade e seus espaços. Porém, ao mesmo tempo, é possível visualizar brechas e potencialidades para que os sujeitos transformem suas práticas sociais. Por conseguinte, o patrimônio, numa perspectiva transformadora, apresenta-se como possibilidade de reconstrução de experiências sensíveis, de repensar a relação dos sujeitos com a história e a memória.

Assim, se na maioria das vezes somos educados para agirmos como "homens da multidão", sem estabelecer com os bens patrimoniais experiências ricas de significado coletivo, existem os momentos de fraturas, embates, (des) mobilizações, contradições e (des) articulações nos processos históricos, nos quais os sujeitos, por meio de suas experiências, exploram o mundo e a si mesmos, produzindo outras formas de sociabilidade $\mathrm{e}$ sensibilidades.

\section{Referências}

BENJAMIN, W. Magia e técnica, arte e política: ensaios sobre literatura e história da cultura. São Paulo: Brasiliense, 2012 (Obras escolhidas; v. 1).

Paris, a capital do século XIX. In: KOTHE, Flávio (Org.). Walter Benjamin. São Paulo: Ática, 1985, p. 30-43.
CONSELHO ESTADUAL DE CULTURA (Espírito Santo). Processo de Tombamento $n^{\circ}$ 09, Vitória, 1980.

Resolução $\mathrm{n}^{\circ}$ 07, de 12 de dezembro de 1985. Diário Oficial [do] Estado do Espírito Santo, Vitória, 16 dez. 1985. Disponível em: < http://secult.es.gov.br/_midias/pdf/22434a68b526a26 84.pdf>. Acesso em: 25 abr. 2015.

Vitória, 2008.

Processo de Restauração $n^{\circ} 43150837 / 08$,

FILIPPON, M. I. A casa do imigrante italiano, a linguagem do espaço de habitar. 2007. $153 \mathrm{f}$. Dissertação (Mestrado em Letras e Cultura Regional)Programa de Pós-Graduação em Letras e Cultura Regional, Universidade de Caxias do Sul, Caxias do Sul, 2007.

FONSECA, M. C. L. O patrimônio em processo: trajetória da política federal de preservação no Brasil. 3. ed. Rio de Janeiro: Editora UFRJ, 2009a.

Para além da pedra e cal: por uma concepção ampla de patrimônio cultural. In: ABREU, R.; CHAGAS, M. (Org.). Memória $e$ patrimônio: ensaios contemporâneos. 2. ed. Rio de Janeiro: Lamparina, 2009b, p. 59-79.

FORTUNA, C. Por entre as Ruínas da cidade: o patrimônio e a memória na construção das identidades sociais. Oficina do CES, Coimbra, n. 61, p. 1-35, set. 1995.

GALZERANI, M. C. B. Práticas de ensino em projeto de educação patrimonial: a produção de saberes educacionais. Pro-posições, Campinas-SP, v. 24, n. 1(70), p. 93-107, jan./abr. 2013.

GASPARINI, S. Santa Teresa: viagem no tempo, 1873-2008. Santa Teresa: Gráfica GSA, 2008.

GAY, P. A experiência burguesa da Rainha Vitória a Freud: a educação dos sentidos. São Paulo: Companhia das Letras, 1988.

GONÇALVES, J. R. S. O patrimônio como categoria do pensamento. In: ABREU, Regina; CHAGAS, M. (Org.). Memória e patrimônio: ensaios contemporâneos. 2. ed. Rio de Janeiro: Lamparina, 2009a, p. 25-33.

Os museus e as cidades. In: ABREU, Regina; CHAGAS, Mário. (Org.). Memória e patrimônio: ensaios contemporâneos. 2. ed. Rio de Janeiro: Lamparina, 2009b, p. 171-186.

GROSSELLI, R. M. Colônias imperiais na terra do café: camponeses trentinos (vênetos e lombardos) 
nas florestas brasileiras. Vitória: Arquivo Público do Estado do Espírito Santo, 2008. (Coleção Canaã; v. 6).

GRILO, S. Casa Lambert. 1980. In: Processo de Tombamento $n^{\circ}$ 09, Vitória, 1980.

HADLER, M. S. D. Trilhos de modernidade: memórias e educação urbana dos sentidos. 2007. 276 f. Tese (Doutorado em Educação) - Faculdade de Educação, Universidade Estadual de Campinas, Campinas, 2007.

LORDELLO, E. Casa Lambert: Santa Teresa-ES. $2013 . \quad$ Disponível em: <http://www.vitruvius.com.br/revistas/read/arquitetur ismo/07. 082/5001>. Acesso em: 22 mar. 2015.

MENEGUELLO, C. Da ruína ao edifício: neogotico, reinterpretação e preservação do passado na Inglaterra vitoriana. Campinas. 2000. 430p. Tese (Doutorado em História) - Instituto de Filosofia e Ciências Humanas, Universidade Estadual de Campinas, Campinas, 2000.

MUNIZ, M. I. P. Cultura e arquitetura: a casa rural do imigrante italiano no Espírito Santo. 2. ed. Vitória: Flor\&cultura, 2009.

A casa rural do imigrante italiano no Espírito Santo. In: CASTIGLIONE, A. H. (Org.). Imigração italiana no Espírito Santo: uma aventura colonizadora. Vitória: UFES, 1998, p. 248-273.

OLIVEIRA, L. L. Cultura é patrimônio: um guia. Rio de Janeiro: Editora FGV, 2008.

Cidade e cotidiano como arena cultural: uma reflexão sobre o Rio de Janeiro. Alpharrabios, Campina Grande, v.1, n.1, 2005. Disponível em: $<$ http://eduep.uepb.edu.br/alpharrabios/v2-n1/v2n1.h tml>. Acesso em: 01 abr.2015.
PINTO JR., A. Professor Joaquim Silva, um autor da história ensinada do Brasil: livros didáticos e educação moderna dos sentidos (1940-1951). 2010. 232 f. Tese (Doutorado em Educação) - Faculdade de Educação, Universidade Estadual de Campinas, Campinas, 2010.

POSENATO, J. Arquitetura da imigração italiana no Espírito Santo. In: CASTIGLIONE, Aurélia Hermínia (Org.). Imigração italiana no Espírito Santo: uma aventura colonizadora. Vitória: UFES, 1998, p. 230- 247.

Arquitetura da imigração italiana no Espírito Santo. Porto Alegre: Posenato Arte \& Cultura, 1997.

RESIDÊNCIA Lambert em 2002. Centro Educacional Leonardo Da Vinci. 2002. Disponível em: <http://www2.davincivix.com.br/davinci.php?are $\mathrm{a}=$ noticias $\& \mathrm{e}=61 \& \mathrm{c}=$ man4aea3a0f85ecc1808> .

Acesso em: 24 ago. 2015.

RICOEUR, P. A memória, a história $e$ o esquecimento. Tradução de Alain François (et al.). São Paulo: Editora da Unicamp, 2007.

SECRETARIA DE TURISMO E CULTURA DE SANTA TERESA (Espírito Santo). Visite a Casa Lambert. [s.d.]. Disponível em: http://santateresa.es.gov.br/noticia/332/Visite-a-CasaLambert.html. Acesso em: 24 ago. 2015.

THOMPSON, E. P. A miséria da teoria ou um planetário de erros: uma crítica ao pensamento de Althusser. Rio de Janeiro: Zahar, 1981.

- Costumes em comum. Estudos sobre a cultura popular tradicional. São Paulo: Companhia das Letras, 1998.

\section{Sobre os autores}

Arnaldo Pinto Junior é Professor da Faculdade de Educação da Universidade Estadual de Campinas. Na mesma universidade, cursou Pós-Graduação, recebendo os títulos de mestre e doutor em 2010. Formou-se bacharel e licenciou-se em História pelo IFCH da Universidade Estadual de Campinas.

Márcia Regina Rodrigues Ferreira é Licenciada em História pela Universidade Federal do Espírito Santo, especialista em Formação Socioeconômica do Brasil pela Universidade Salgado de Oliveira- UNIVERSO. Mestra em Educação pelo Programa de Pós-Graduação em Educação da Universidade Federal do Espírito Santo.

Recebido em novembro de 2016. Aprovado em fevereiro de 2017. 